\title{
Increased genetic gains in sheep, beef and dairy breeding programs from using female reproductive technologies combined with optimal contribution selection and genomic breeding values
}

\author{
Tom Granleese ${ }^{1,2^{*}}$, Samuel A. Clark², Andrew A. Swan ${ }^{1,3}$ and Julius H. J. van der Werf ${ }^{1,2}$
}

\begin{abstract}
Background: Female reproductive technologies such as multiple ovulation and embryo transfer (MOET) and juvenile in vitro embryo production and embryo transfer (JIVET) can boost rates of genetic gain but they can also increase rates of inbreeding. Inbreeding can be managed using the principles of optimal contribution selection (OCS), which maximizes genetic gain while placing a penalty on the rate of inbreeding. We evaluated the potential benefits and synergies that exist between genomic selection (GS) and reproductive technologies under OCS for sheep and cattle breeding programs.

Methods: Various breeding program scenarios were simulated stochastically including: (1) a sheep breeding program for the selection of a single trait that could be measured either early or late in life; (2) a beef breeding program with an early or late trait; and (3) a dairy breeding program with a sex limited trait. OCS was applied using a range of penalties (severe to no penalty) on co-ancestry of selection candidates, with the possibility of using multiple ovulation and embryo transfer (MOET) and/or juvenile in vitro embryo production and embryo transfer (JIVET) for females. Each breeding program was simulated with and without genomic selection.

Results: All breeding programs could be penalized to result in an inbreeding rate of $1 \%$ increase per generation. The addition of MOET to artificial insemination or natural breeding (AI/N), without the use of GS yielded an extra 25 to $60 \%$ genetic gain. The further addition of JIVET did not yield an extra genetic gain. When GS was used, MOET and MOET + JIVET programs increased rates of genetic gain by 38 to $76 \%$ and 51 to $81 \%$ compared to Al/ $\mathrm{N}$, respectively.

Conclusions: Large increases in genetic gain were found across species when female reproductive technologies combined with genomic selection were applied and inbreeding was managed, especially for breeding programs that focus on the selection of traits measured late in life or that are sex-limited. Optimal contribution selection was an effective tool to optimally allocate different combinations of reproductive technologies. Applying a range of penalties to co-ancestry of selection candidates allows a comprehensive exploration of the inbreeding vs. genetic gain space.
\end{abstract}

\section{Background}

Female reproductive technologies such as multiple ovulation and embryo transfer (MOET) and juvenile in vitro

\footnotetext{
*Correspondence: tgranle2@une.edu.au

${ }^{2}$ School of Environmental and Rural Science, University of New England,

Armidale 2351, Australia

Full list of author information is available at the end of the article
}

fertilization and embryo transfer (JIVET) can be used by breeders to accelerate genetic gain in livestock breeding programs. These technologies allow an increase of selection intensity placed on females and they can also reduce the optimal age at which animals are selected, and thus decrease generation intervals in the breeding program. 
Prior to genomic selection (GS) [1], MOET breeding programs were reported to increase genetic gain in dairy breeding programs by up to $30 \%$ by increasing the selection intensity of females [2]. Furthermore, if MOET was used and the age of selection candidates decreased, breeding schemes would increase genetic gain by another $9 \%$ [3]. These gains were similar also in beef and sheep breeding programs, for which MOET was estimated to yield an extra 67 to $100 \%$ of genetic gain for beef $[4,5]$ and 17 to $74 \%$ for sheep [6-8]. However, all these studies agreed that MOET breeding programs would also increase annual rates of inbreeding by up to $110 \%$ compared to traditional mating programs. Some of these increased rates of inbreeding could have even been underestimated due to reductions in genetic variance and to the assumption that the size of a family and family numbers were constant [9]. For example, the stochastic simulation of Villanueva et al. [10] showed that inbreeding rates increased by $17 \%$ when there is variability between donors in embryo production compared to when embryo numbers are assumed fixed.

When JIVET became commercially viable in the 1990s, selection of donors for JIVET was often based on estimated breeding values (EBV) that had low accuracy and that were highly correlated among siblings due to the great emphasis put on common family information. In this scenario, it is difficult to realize high rates of genetic gain and maintain sustainable rates of inbreeding. Marker-assisted selection [11] and more recently genomic selection [1] have facilitated greater accuracy of EBV and lower correlations of EBV between relatives [12], particularly in younger stock that have not had any performance measurements yet, or if the trait is sex-limited (i.e. milk production), is hard-to-measure (i.e. carcass traits), or has a low heritability (i.e. reproduction).

Recently, some studies have assessed some of the synergies that may exist between the use of reproductive technologies and genomic selection. Using stochastic simulation, Pederson et al. [13] found that genomic selection and MOET on $50 \%$ of nucleus dairy breeding cows resulted in a $23 \%$ increase in genetic gain with no significant increase in inbreeding. Pryce et al. [14] used a deterministic model for a dairy breeding program to show a $98 \%$ increase in genetic gain per year when exclusively using JIVET and genomic selection compared to a progeny test program, but with an increase of inbreeding rate by $65 \%$. It is important for practical breeding programs to consider numbers of female selection candidates consigned to MOET and JIVET since both are expensive and labor intensive procedures. It is also important to investigate strategies to slow rates of inbreeding which can be accelerated by these technologies.
It is clear from previous studies $[3-8,10,13,14]$ that increasing selection intensity for females in breeding programs can significantly increase rates of inbreeding. Optimal contribution selection (OCS) is a method that balances longer-term genetic merit and genetic diversity in breeding populations. OCS can determine the optimal levels of the genetic contributions of selection candidates but these are often limited by physiological parameters under natural mating. OCS could, however, be an effective tool to assign female reproductive technologies to individual females in breeding programs, while also assigning optimal contributions to males. For a fair comparison and a realistic assessment of the value of reproductive technologies and GS and their potential synergies, comparisons of breeding programs should be done at similar inbreeding rates.

The method developed by Wray and Goddard [15] that applies multiple penalties to co-ancestry while allocating optimal genetic contributions from selection candidates allows the entire selection space between genetic gain and inbreeding to be explored rather than targeting a specific point as demonstrated by Meuwissen [16]. Wray and Goddard's [15] method is useful to investigate the optimal balance between genetic gain and inbreeding. Since OCS allows genetic diversity to be maintained and genetic contributions to be optimized, the synergies that exist between GS and reproductive technologies can be further explored via simulation of breeding programs.

The objective of this study was to assess the value of using female reproduction technologies combined with GS and compare their benefits in beef and dairy cattle and sheep breeding programs, when the aim is to increase rates of genetic gain while keeping inbreeding at sustainable levels. We applied OCS with various penalties on inbreeding and optimized the number of females to be used in MOET or JIVET with regard to genetic gain and inbreeding.

\section{Methods}

\section{Simulation}

Stochastic simulation was used to model a number of closed nucleus breeding schemes. The number of progeny born each year in a closed nucleus was 250, 250 and 600 for sheep, beef and dairy cattle, respectively. For each scenario, we generated a base population of unrelated animals, and subsequently established a 20-year breeding program with overlapping generations. There was an annual random death rate of $10 \%$. Phenotypes and selection were for a single trait for each breeding program. The genetic values for the base individuals were simulated using a polygenic model as: 


$$
a_{i}=z \sigma_{a}
$$

where $z$ is a random variable drawn from a standard normal distribution and $\sigma_{a}$ is the genetic standard deviation of the trait. Breeding values for the subsequent generations were obtained using:

$$
a_{i}=\left(\left(a_{s i}+a_{d i}\right) / 2\right)+M S_{i},
$$

where $a_{s i}$ and $a_{d i}$ are the true breeding values of the sire and dam of animal $i$, respectively, and $M S_{i}$ is the Mendelian sampling effect for individual $i$, which was simulated as:

$$
M S_{i}=z \cdot \sigma_{a} \sqrt{\left(.5\left(1-\bar{F}_{i}\right)\right)}
$$

where $\overline{F_{i}}$ is the average inbreeding coefficient of the parents of individual $i$. Phenotypes were then simulated by adding a random error term to $a_{i}$, such that each trait had a heritability of 0.3 in the base population.

We simulated a number of single-trait scenarios across species that differed in gestation length and whether trait measurement was before or after selection or sex-limited. Phenotypic information was available on selection candidates when the trait could be measured: (1) on both sexes within 6 months of age in sheep (e.g. weight and scan traits); (2) at 2 years of age in sheep on both sexes (e.g. adult wool production); (3) within the first year in beef cattle on both sexes (e.g. weaning and yearling weight); (4) at 19 months of age, after sexual maturity, in beef cattle on both sexes (e.g. 600 day live weight); (5) a sex-limited trait measured on females at 27 months of age (e.g. milk production).

\section{Eligibility and selection of males Sheep}

Rams were eligible for selection at 7 months of age and again at 19 months of age. Thereafter, they were culled if not selected at 19 months of age.

\section{Beef cattle}

Bulls were eligible for selection at 15 and 27 months of age. Thereafter, they were culled if not selected at 27 months of age.

\section{Dairy cattle}

In breeding programs without GS, bulls were eligible for pre-selection for progeny testing at 15 months of age. Young bulls were selected for progeny testing by conducting the OCS procedure with the 75 highest allocations of contributions selected. By the age of 4.5 years, each bull had 50 daughters (in external herds) with a lactation record. The progeny tested bulls were first eligible for mating in the closed nucleus at 4 years of age and all were kept as selection candidates at 5-years of age. Any bull not selected at 6 years of age or older was culled and all bulls were culled at 9 years of age. Similar to Pryce et al. [14], breeding programs that incorporated GS made bulls eligible for mating at 15 months old. After GS, at 15 months of age, OCS of the top 75 males based on optimal contribution was performed and they were then used in a progeny-testing program with 50 recorded daughters, similar to the breeding program without GS. In breeding programs where GS was used, all bulls that were selected for progeny-testing were eligible for selection every year up to 5 years of age.

\section{Genomic selection}

Some breeding programs had a scenario where genomic selection was used for all animals born in the nucleus. Genomic information was modeled following the method of Dekkers [17], which simulates a genomic estimated breeding value (GEBV) as a correlated trait with a heritability of 0.99 and a correlation $r$ to the measured trait, where $r$ is the accuracy of the GEBV. The accuracy of the GEBV was assumed to be 0.5 for sheep [18], 0.5 for beef cattle [19] and 0.7 for dairy cattle [20]. All animals received a GEBV at birth and the GEBV was combined with phenotypic information when calculating breeding values.

\section{Estimation of breeding values}

Each year, EBV were estimated using best linear unbiased prediction (BLUP). The model assumed used was:

$$
\mathbf{y}=\mathbf{1}_{n} \mu+\mathbf{Z a}+\mathbf{e},
$$

where $\mathbf{y}$ is a vector of phenotypes, $\mu$ is the mean, $\mathbf{1}_{\boldsymbol{n}}$ is a vector of $1 \mathrm{~s}, \mathbf{Z}$ is a design matrix allocating records to breeding values, $\mathbf{a}$ is a vector of breeding values with $\operatorname{var}(\mathbf{a})=\mathbf{A} \sigma_{a}^{2}$ where $\mathbf{A}$ is the numerator relationship matrix and $\sigma_{a}^{2}$ is the additive genetic variance, $\mathbf{e}$ is a random effect. All data from the base population onwards were used for genetic evaluation, including data on the progeny of sires that were progeny-tested.

\section{Optimal contribution selection}

Optimal contribution selection was implemented using the approach of Wray and Goddard's [15], balancing the average genetic merit $(\mathrm{M})$ of selected individuals with the average co-ancestry among selected individuals $(\mathrm{C})$, both weighted by their contributions to the next generation. Average genetic merit of the selected individuals was evaluated as:

$$
\mathbf{M}=\mathbf{x}^{\prime} \hat{\mathbf{a}},
$$

where $\hat{\mathbf{a}}$ is a vector of EBV and $\mathbf{x}$ is a vector of genetic contributions of selection candidate animals, with values 
in $\mathbf{x}$ summing to 0.5 for each of the sexes. The $\mathbf{x}$ vector contributions for females were capped at a maximum of the equivalent of four offspring per female when MOET or JIVET was used and the equivalent of 1 for the scenarios with only artificial insemination or natural mating $(\mathrm{AI} / \mathrm{N})$. After contributions were assigned to females, the number of required matings could be determined for males. The maximum number of matings for a single male was then capped at the total number of female matings. Price and Storn's [21] evolutionary algorithm was used to find optimal solutions for $\mathrm{M}+\mathrm{C}$. Once female and male candidates were assigned a mating, they were placed on a mating list. Matings were assigned at random and females were given a chance of a random number of live progeny according to a distribution shown in Table 1. One mating could result in multiple progeny via twins with $\mathrm{AI} / \mathrm{N}$, and via embryos implanted in recipients in MOET and JIVET programs.

Inbreeding rates were managed by penalizing the average co-ancestry among selected animals, which was computed as:

$$
\mathrm{C}=\lambda \mathbf{x}^{\prime} \mathbf{A x},
$$

where $\mathbf{A}$ is the $(\mathrm{n} \times \mathrm{n})$ relationship matrix among all candidates based on pedigree information and $\lambda$ is a penalty that can be set to result in different rates of inbreeding. Price and Storn's [21] evolutionary algorithm was then used to find optimal contributions as in the vector $\mathbf{x}$ by maximizing $M+C$ for a given value of $\lambda$. These $\lambda$ values evaluated included $(0,-15,-25,-35,-50,-75,-100$, $-250,-1000,-9999)$. The values of $\lambda$ were selected to explore the entire selection space of inbreeding vs genetic gain, which when combined, would form a frontier of possible outcomes. Smaller penalties will result in higher levels of co-ancestry among selected candidates, with potentially higher rates of genetic gain and harsh penalties will result in higher genetic diversity with lower rates of genetic gain.

\section{Breeding programs}

Three breeding program structures were simulated that differed in the use of reproductive technologies. The first breeding program used only natural mating and/ or AI and was simulated as a control. The second breeding program examined the effect of adding MOET to the breeding program, and the third examined the effect of MOET and JIVET combined. The number of offspring that each dam produced under the various reproductive technologies was randomly assigned from a range of offspring based on previous studies [22-26] (Table 1). Females were only offered one chance of being allocated a reproductive technology in each selection round. If no offspring were born, the female was carried as a dry animal to the next round of selection.

Table 1 Probability of producing a certain number of live progeny per female per mating for artificial insemination (AI) or natural mating (AI/N), MOET and JIVET in different species

\begin{tabular}{|c|c|c|c|c|c|c|}
\hline $\begin{array}{l}\text { Progeny number/program } \\
\text { Species }\end{array}$ & $\begin{array}{l}\mathrm{Al} / \mathrm{N} 12^{\mathrm{a}} \\
\text { Sheep }\end{array}$ & $\begin{array}{l}\mathrm{Al} / \mathrm{N}^{\mathrm{a}} \\
\text { Sheep }\end{array}$ & $\begin{array}{l}\mathrm{Al} / \mathrm{N}^{\mathrm{c}} \\
\text { Beef }\end{array}$ & $\begin{array}{l}\mathrm{Al}^{\mathrm{d}} \\
\text { Dairy }\end{array}$ & $\begin{array}{l}\text { MOET }^{\mathbf{b}, \mathbf{e}} \\
\text { All }\end{array}$ & $\begin{array}{l}\text { JIVET }^{\mathbf{b}} \\
\text { All }\end{array}$ \\
\hline 0 & 0.40 & 0.10 & 0.07 & 0.15 & 0.10 & 0.25 \\
\hline 1 & 0.58 & 0.70 & 0.92 & 0.85 & 0.05 & 0.05 \\
\hline 2 & 0.02 & 0.20 & 0.01 & 0.00 & 0.05 & 0.18 \\
\hline 3 & 0.00 & 0.00 & 0.00 & 0.00 & 0.15 & 0.18 \\
\hline 4 & 0.00 & 0.00 & 0.00 & 0.00 & 0.25 & 0.10 \\
\hline 5 & 0.00 & 0.00 & 0.00 & 0.00 & 0.15 & 0.10 \\
\hline 6 & 0.00 & 0.00 & 0.00 & 0.00 & 0.13 & 0.07 \\
\hline 7 & 0.00 & 0.00 & 0.00 & 0.00 & 0.07 & 0.04 \\
\hline 8 & 0.00 & 0.00 & 0.00 & 0.00 & 0.05 & 0.03 \\
\hline Average number of progeny & 0.62 & 1.1 & 0.94 & 0.85 & 4.02 & $8.37^{f}$ \\
\hline Range of progeny possible & $0-2$ & $0-2$ & $0-2$ & $0-1$ & $0-8$ & $0-24$ \\
\hline
\end{tabular}

Al/N7 probability for a ewe at 12 months of age of having a lamb

a [22]

b [23]

c [24]

${ }^{d}$ [25]

e [26]

f Predicted average of total progeny of three JIVET matings 


\section{Breeding program 1: artificial insemination/natural mating $(A I / N)$}

Ewes were eligible for selection at 7 and 19 months of age. Heifers and cows' were eligible for selection at 15 and 27 months of age in the beef and dairy breeding programs. Ewes and cows were culled if not selected at 19 and 27 months of age, respectively.

\section{Breeding program 2: $A I / N+M O E T$}

Eligibility of females for $\mathrm{AI} / \mathrm{N}$ or MOET was the same as in the $\mathrm{AI} / \mathrm{N}$ breeding program because MOET can only be performed on sexually mature females, including young ewes that are just entering puberty [27]. Females that were selected to contribute four offspring based on OCS were assigned to MOET. Females selected to contribute between one and three offspring were assigned to $\mathrm{AI} / \mathrm{N}$. Eligibility and culling of females were the same as in the $\mathrm{AI} / \mathrm{N}$ breeding programs. In all MOET programs, dams were given the chance of having 0 to 8 offspring, with an average of 4 (Table 1 ). Females were only assigned one male mate for each $\mathrm{AI} / \mathrm{N}$ or MOET breeding.

\section{Breeding program 3: $A I / N+M O E T+$ JIVET}

The third breeding program added the possibility for juvenile females to be candidates for selection through the use of JIVET. Only juvenile ewes and heifers were eligible for JIVET and they were not eligible for $\mathrm{AI} / \mathrm{N}$ or MOET in either species. Juvenile females that were selected in OCS to four offspring were assigned JIVET matings. Sexually mature females that were selected to contribute three offspring were assigned to MOET, females selected to contribute less than three offspring were assigned an AI mating, and females that were selected to contribute less than one offspring were not used.

Due to the possibility of using multiple sires in JIVET, three separate matings were assigned to females for JIVET in the same mating period, whereas $\mathrm{AI} / \mathrm{N}$ and MOET females only received one mating. Selected juvenile females could have between 0 and 8 offspring for each of the three matings, with an average of 2.8 live offspring per mating (Table 1).

Ewes were 1 month old at selection for JIVET. Sheep breeding programs required a mid-year JIVET mating since the timing of JIVET-on-JIVET programs do not fit into annual breeding programs. During the mid-year mating, all ewe selection candidates (including mature ewes) were entered into OCS but only JIVET allocations were executed despite AI and MOET matings being allocated to the mature ewes. As these matings allocated to mature ewes did not yield any progeny, the following round of selection ignored those allocated matings. OCS took into account if ewes had contributed 6 months earlier. In beef and dairy breeding programs, heifers were 3 months old when assigned to JIVET and did not require a mid-year mating like sheep as cattle have a nine month gestation period.

\section{Comparison of breeding programs}

Each breeding program was run for 20 years and replicated 75 times. Breeding programs were compared based on average annual genetic gains and average annual rates of inbreeding for years 6 to 20, i.e. after the Bulmer equilibrium [28] was reached. Inbreeding was calculated annually as the average inbreeding coefficient of the entire drop of animals born that year using pedigree information. The average annual inbreeding to be displayed in the figures was calculated as the inbreeding increase per year averaged from years 6 to 20 of the simulation. Inbreeding per generation was also calculated due to overlapping generations existing in the simulations. Inbreeding per generation was calculated by matching the average inbreeding coefficient over the last 10 years with the number of generations in $n$ years where:

$$
\text { NGens }=\left(\frac{n}{L}\right),
$$

where $n$ is the number of breeding years and $L$ is the average generation interval over the final 15 years of the simulated breeding program. Generation interval for each individual was calculated as average age of parents at age of birth. The annual generation interval was calculated as the average generation interval of the entire drop born each year.

\section{Results}

\section{Differences between breeding programs without genomic} selection

At moderate ( $1 \%$ per generation) to high ( $>1.5 \%$ per generation) levels of inbreeding MOET outperformed AI in all cases by 25 to $50 \%$. At lower inbreeding levels, MOET provided up to 17 to $65 \%$ more genetic gain than $\mathrm{AI} / \mathrm{N}$, particularly for late (Figs. 1, 2) and sex-limited traits (Fig. 3). When inbreeding was heavily penalized, there was little genetic gain or inbreeding. In the early measured sheep trait, JIVET yielded 4 to $10 \%$ more genetic gain than MOET (Fig. 4). However, for a late sheep trait and for both beef traits and a sex-limited dairy trait, there was no significant difference in genetic gain between the JIVET and MOET breeding programs (Figs. 1, 2, 3, 5) although some matings were allocated to JIVET (Table 2). As the penalty on inbreeding increased, generation intervals increased and genetic gain decreased (Table 3). It should also be noted that "unpenalized" inbreeding levels in Tables 3 and 4 are of the results of setting $\lambda$ to zero which are similar to results from truncation selection. 


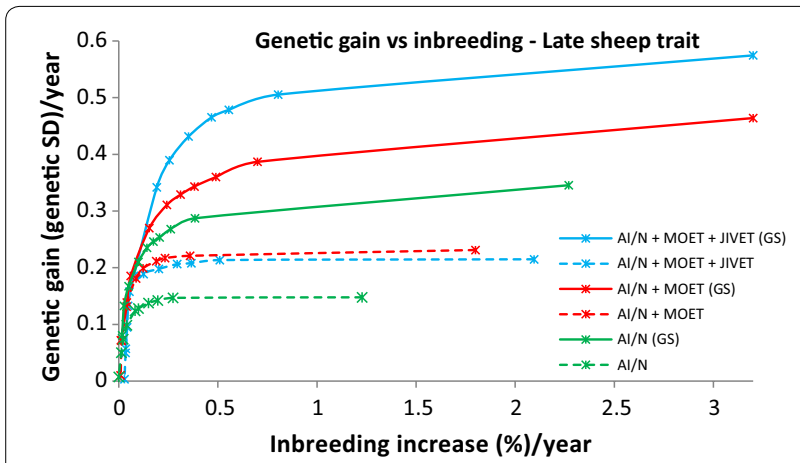

Fig. 1 Average annual genetic gain (genetic standard deviations) and rate of inbreeding (\%) with selection on a late measured trait in sheep using reproductive technologies with and without genomic selection. Data points represent different penalties on coancestry, with no penalty on the far right and a high penalty on the far left

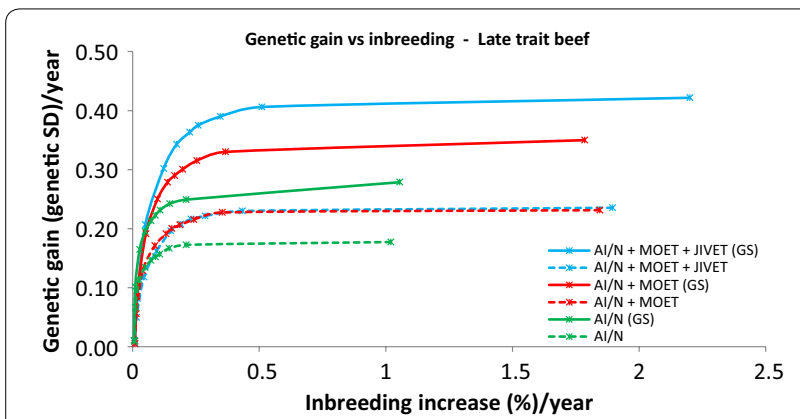

Fig. 2 Average annual genetic gain (genetic standard deviations) and rate of inbreeding (\%) with selection on a late measured trait in beef using reproductive technologies with and without genomic selection. Data points represent different penalties on coancestry, with no penalty on the far right and a high penalty on the far left

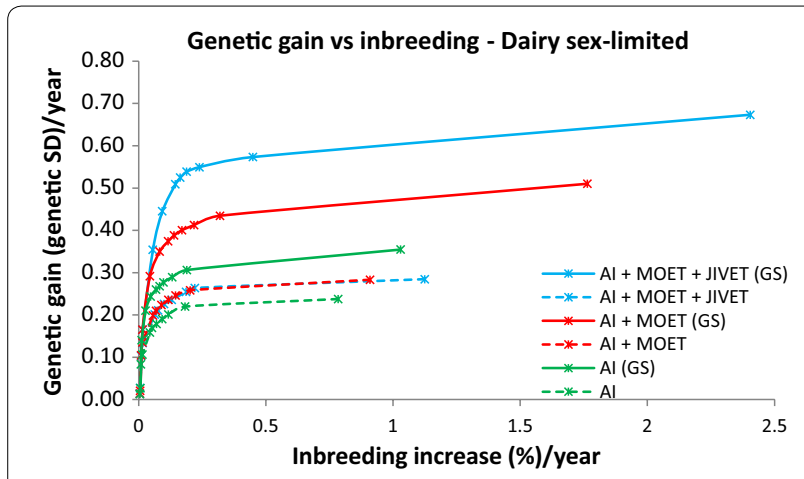

Fig. 3 Average annual genetic gain (genetic standard deviations) and rate of inbreeding (\%) in dairy cattle using reproductive technologies with and without genomic selection. Data points represent different penalties on coancestry, with no penalty on the far right and a high penalty on the far left

\section{Differences between breeding programs with genomic selection}

When GS was implemented in breeding programs, programs using JIVET yielded the largest genetic gain, followed by programs using MOET for all species and traits (Table 3; Figs. 1, 2, 3, 4, 5). The largest differences in genetic gain between JIVET and MOET breeding programs were observed for late traits in sheep and beef cattle and for a sex-limited trait in dairy cattle, with differences ranging from 24 to $32 \%$ of genetic gain with MOET at moderate inbreeding levels. Differences in annual genetic gain between $\mathrm{MOET}$ and $\mathrm{AI} / \mathrm{N}$ were largest for early measured traits, ranging from 41 to $43 \%$ of genetic gain with AI (Tables 3,4). The use of both JIVET and MOET decreased generation intervals, with programs using JIVET displaying the most significant decrease for all species and traits (Table 3).

\section{Impact of genomic selection on breeding programs}

The use of GS decreased generation intervals and increased genetic gain across all species and traits (Table 3). Genomic selection increased genetic gain by 37 to $143 \%$ for breeding programs using JIVET, 23 to $77 \%$ for breeding programs using MOET and 23 to $93 \%$ for AI/N breeding programs (Table 4). These gains were proportionally higher for late measured traits in sheep (Fig. 1), beef cattle (Fig. 2) and dairy cattle (Fig. 3). The use of GS in early measured traits for sheep (Fig. 4) and beef cattle (Fig. 5) still produced 20 to $40 \%$ more genetic gain when combined with reproductive technologies.

When inbreeding was not heavily penalized $(>0.5 \%$ inbreeding per generation), the allocation of reproductive technologies increased with the use of GS. When comparing breeding programs with and without GS, there were more JIVET matings with GS at the expense of MOET matings, and this re-allocation was more pronounced for late measured traits and in dairy cattle (Table 3).

\section{Discussion}

\section{Breeding programs}

Our results show that, as in prior studies, using female reproductive technologies increases genetic gain when compared to traditional breeding programs. Moreover, we found that the use of female reproductive technologies in combination with the implementation of genomic selection increased rates of genetic gain even more. However, we also observed in all scenarios that if inbreeding was not penalized, large inbreeding coefficients could be accumulated over time. This study demonstrates the benefits of optimizing the allocation of females to 


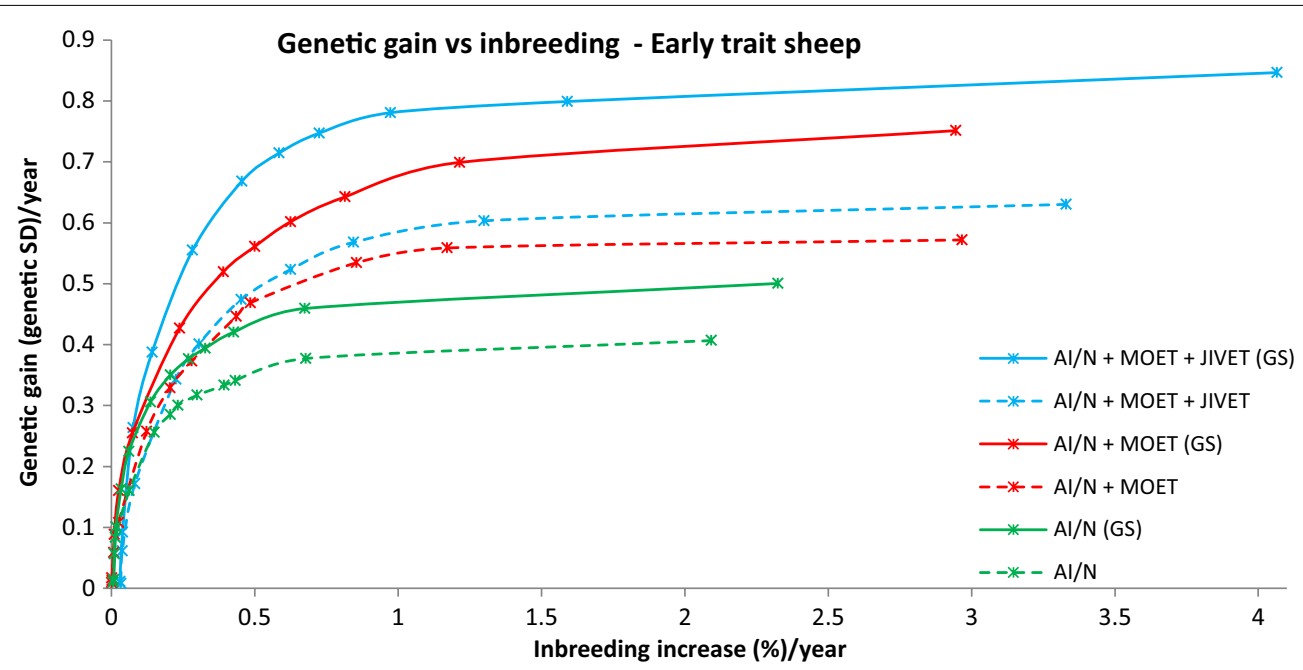

Fig. 4 Average annual genetic gain (genetic standard deviations) and rate of inbreeding (\%) with selection on an early measured trait in sheep using reproductive technologies with and without genomic selection. Data points represent different penalties on coancestry, with no penalty on the far right and a high penalty on the far left

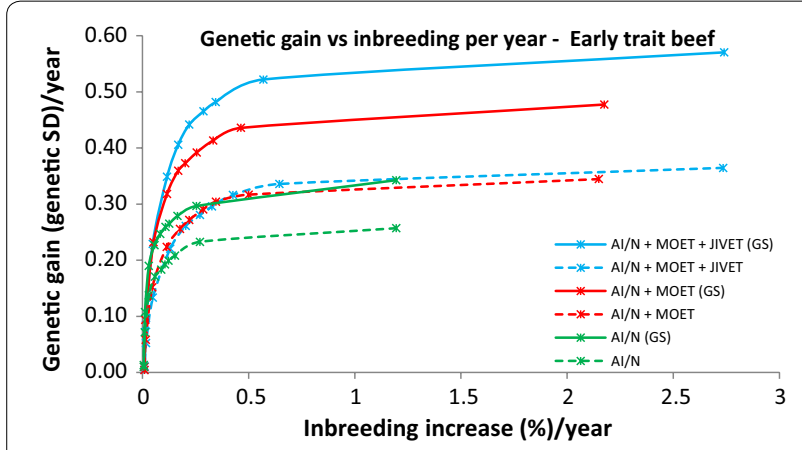

Fig. 5 Average annual genetic gain (genetic standard deviations) and rate of inbreeding (\%) with selection on an early measured trait in beef using reproductive technologies with and without genomic selection. Data points represent different penalties on coancestry, with no penalty on the far right and a high penalty on the far left

reproductive technologies through the use of optimal contribution selection, which resulted in increased rates of genetic gain under sustainable rates of inbreeding. Combining MOET with GS yielded 25 to $50 \%$ more genetic gain compared to AI and combining JIVET with GS increased genetic gain up to $143 \%$ without increasing the rate of inbreeding.

Genomic selection resulted in clear benefits between breeding strategies for all traits, species and breeding programs using different technologies. When comparing breeding programs with and without GS, increases in genetic gains from the use of GS ranged from 33 to $143 \%$ for JIVET programs, from 37 to $77 \%$ for MOET programs and from 29 to $93 \%$ for AI/N programs (Tables 3,
4). When comparing programs that used GS, JIVET led to 15 to $43 \%$ greater genetic gain than MOET breeding programs. We also observed a 38 to $76 \%$ greater genetic gain for MOET breeding programs compared to $\mathrm{AI} / \mathrm{N}$ breeding programs when GS was implemented in both breeding programs. These gains of MOET over AI and JIVET over MOET were due to greater accuracies of EBV at selection of young selection candidates and lower correlations between the EBV of siblings. Genomic selection allows an increase of selection accuracy at the age of first selection and this increase is greatest for late and sexlimited traits. Genomic information increases accuracy of EBV by explaining within-family variance due to Mendelian sampling [12], which is important when selecting animals early because without GS there is little information about this component. Moreover, the Bulmer effect reduces the between-family variance and, therefore, contributes less to future genetic gains than the withinfamily variance [29]. Dekkers [17] concluded that highly accurate (0.8) GEBV could increase genetic gain by 21 and $81 \%$ over a traditional phenotypic selection program for traits with a heritability of 0.3 and 0.1 , respectively. These extra gains from GS depend on whether traits have been measured on selection candidates at the time of first selection. In dairy cattle, we used accurate GEBV for GS (0.7) and observed that GS increased rates of genetic gain in traditional AI programs by $52 \%$ (Tables 3,4 ). Using GS in sheep and beef cattle programs, with a lower accuracy of GEBV (0.5), increased rates of genetic gain by 29 to $93 \%$, depending on species and when the trait was measured (Tables 3, 4). Genomic predictions in beef cattle and sheep are typically less accurate than in dairy cattle due 
Table 2 Proportion of selected females assigned each type of mating in each breeding program when rate of inbreeding is $1 \%( \pm 0.05 \%)$ per generation for sheep, beef and dairy

\begin{tabular}{|c|c|c|c|c|c|c|}
\hline & $\mathrm{Al} / \mathrm{N}$ & MOET & JIVET & Nb of females selected ${ }^{a}$ & $\mathrm{Nb}$ of males used ${ }^{\mathrm{a}}$ & Nb of females per male \\
\hline \multicolumn{7}{|l|}{ Early trait sheep } \\
\hline $\mathrm{Al} / \mathrm{N}+\mathrm{MOET}+$ JIVET (GS) & 0.37 & 0.24 & 0.39 & 55 & 23 & 2.4 \\
\hline $\mathrm{Al} / \mathrm{N}+\mathrm{MOET}+$ JIVET & 0.42 & 0.37 & 0.21 & 65 & 24 & 2.7 \\
\hline $\mathrm{Al} / \mathrm{N}+\mathrm{MOET}(\mathrm{GS})$ & 0.41 & 0.59 & & 95 & 23 & 4.0 \\
\hline $\mathrm{Al} / \mathrm{N}+\mathrm{MOET}$ & 0.5 & 0.5 & & 110 & 23 & 4.8 \\
\hline $\mathrm{Al} / \mathrm{N}(\mathrm{GS})$ & 1 & & & 243 & 28 & 8.7 \\
\hline $\mathrm{Al} / \mathrm{N}$ & 1 & & & 243 & 31 & 8.0 \\
\hline \multicolumn{7}{|l|}{ Late trait sheep } \\
\hline $\mathrm{Al} / \mathrm{N}+\mathrm{MOET}+$ JIVET (GS) & 0.36 & 0.18 & 0.46 & 51 & 28 & 1.8 \\
\hline $\mathrm{Al} / \mathrm{N}+\mathrm{MOET}+$ JIVET & 0.42 & 0.29 & 0.29 & 59 & 27 & 2.2 \\
\hline $\mathrm{Al} / \mathrm{N}+\mathrm{MOET}(\mathrm{GS})$ & 0.34 & 0.66 & & 110 & 27 & 4.1 \\
\hline $\mathrm{Al} / \mathrm{N}+\mathrm{MOET}$ & 0.45 & 0.55 & & 110 & 29 & 3.8 \\
\hline $\mathrm{Al} / \mathrm{N}(\mathrm{GS})$ & 1.00 & & & 245 & 33 & 7.4 \\
\hline $\mathrm{Al} / \mathrm{N}$ & 1.00 & & & 244 & 32 & 7.7 \\
\hline \multicolumn{7}{|l|}{ Early trait beef } \\
\hline $\mathrm{Al} / \mathrm{N}+\mathrm{MOET}+$ JIVET (GS) & 0.24 & 0.32 & 0.44 & 47 & 19 & 2.5 \\
\hline $\mathrm{Al} / \mathrm{N}+\mathrm{MOET}+$ JIVET & 0.26 & 0.35 & 0.39 & 57 & 20 & 2.9 \\
\hline $\mathrm{Al} / \mathrm{N}+\mathrm{MOET}(\mathrm{GS})$ & 0.34 & 0.66 & & 98 & 18 & 5.4 \\
\hline $\mathrm{Al} / \mathrm{N}+\mathrm{MOET}$ & 0.34 & 0.66 & & 100 & 19 & 5.3 \\
\hline $\mathrm{Al} / \mathrm{N}(\mathrm{GS})$ & 1.00 & & & 276 & 14 & 19.7 \\
\hline $\mathrm{Al} / \mathrm{N}$ & 1.00 & & & 277 & 14 & 19.8 \\
\hline \multicolumn{7}{|l|}{ Late trait beef } \\
\hline $\mathrm{Al} / \mathrm{N}+\mathrm{MOET}+\mathrm{JIVET}(\mathrm{GS})$ & 0.25 & 0.34 & 0.41 & 51 & 14 & 3.6 \\
\hline $\mathrm{Al} / \mathrm{N}+\mathrm{MOET}+$ JIVET & 0.26 & 0.40 & 0.34 & 57 & 15 & 4.1 \\
\hline $\mathrm{Al} / \mathrm{N}+\mathrm{MOET}(\mathrm{GS})$ & 0.32 & 0.68 & & 97 & 15 & 7.7 \\
\hline $\mathrm{Al} / \mathrm{N}+\mathrm{MOET}$ & 0.35 & 0.65 & & 101 & 16 & 5.0 \\
\hline $\mathrm{Al} / \mathrm{N}(\mathrm{GS})$ & 1.00 & & & 277 & 15 & 18.1 \\
\hline $\mathrm{Al} / \mathrm{N}$ & 1.00 & & & 279 & 16 & 17.2 \\
\hline \multicolumn{7}{|l|}{ Dairy } \\
\hline $\mathrm{Al}+\mathrm{MOET}+\operatorname{JIVET}(\mathrm{GS})$ & 0.38 & 0.28 & 0.34 & 143 & 39 & 3.7 \\
\hline $\mathrm{Al}+\mathrm{MOET}+$ JIVET & 0.47 & 0.35 & 0.18 & 167 & 41 & 4.1 \\
\hline $\mathrm{Al}+\mathrm{MOET}(\mathrm{GS})$ & 0.47 & 0.53 & & 265 & 40 & 6.7 \\
\hline $\mathrm{Al}+\mathrm{MOET}$ & 0.44 & 0.56 & & 263 & 34 & 7.7 \\
\hline $\mathrm{Al}(\mathrm{GS})$ & 1.00 & & & 646 & 59 & 11.0 \\
\hline $\mathrm{Al}$ & 1.00 & & & 652 & 41 & 15.8 \\
\hline
\end{tabular}

a All standard errors of means (SEM) for total numbers of ewes, cows and males were less than 1.2, 2.7 and 0.18 , respectively

to the extensive and multi-breed aspect of these industries, which makes it more difficult to generate training populations that sustain high accuracies. Studies in sheep that assumed maximum accuracies of GEBV of 0.5 showed that GS increased genetic gain by $21 \%$ in terminal sire breeds and up to $39 \%$ in fine wool Merino sheep [30].

\section{Optimal contribution selection}

While many previous studies have evaluated the shortterm benefits of reproductive technologies, they did not all explore how the rate of inbreeding can be minimized or reduced. Wray and Goddard [15] developed a selection principle to manage rates of inbreeding through a penalty method. Other studies implement OCS by maximizing genetic gain at a specific rate of inbreeding [16, $31,32]$. Together, these methods have demonstrated that maintaining a high level of genetic gain at set rates of inbreeding can be achieved. We used a range of inbreeding penalties to create 'frontiers' of genetic gain versus inbreeding, thereby clearly showing the balance that can be achieved (Figs. 1, 2, 3, 4, 5), rather than targeting 
Table 3 Average generation interval $(L)$ and annual genetic gain ( $\Delta \mathrm{G}$ in $\sigma_{a}$ units) across 75 replicates at various rates of inbreeding $( \pm 0.05 \%)$ per generation for sheep, beef and dairy traits

\begin{tabular}{|c|c|c|c|c|c|c|}
\hline \multirow{2}{*}{$\begin{array}{l}\text { Inbreeding rate } \\
\text { (\%/generation) }\end{array}$} & \multicolumn{2}{|l|}{0.5} & \multicolumn{2}{|l|}{1.0} & \multicolumn{2}{|c|}{ Unpenalized } \\
\hline & $\mathbf{L}$ & $\Delta \mathrm{G}$ & $\mathbf{L}$ & $\Delta \mathrm{G}$ & $\mathbf{L}$ & $\Delta \mathrm{G}$ \\
\hline \multicolumn{7}{|l|}{ Early trait sheep } \\
\hline $\mathrm{Al} / \mathrm{N}+\mathrm{MOET}+\mathrm{JIVET}(\mathrm{GS})$ & 1.06 & 0.67 & 1.01 & 0.77 & 0.92 & 0.85 \\
\hline $\mathrm{Al} / \mathrm{N}+\mathrm{MOET}(\mathrm{GS})$ & 1.73 & 0.43 & 1.39 & 0.63 & 1.23 & 0.75 \\
\hline $\mathrm{Al} / \mathrm{N}(\mathrm{GS})$ & 2.04 & 0.39 & 1.94 & 0.44 & 1.84 & 0.50 \\
\hline $\mathrm{Al} / \mathrm{N}+\mathrm{MOET}+\mathrm{JIVET}$ & 1.30 & 0.40 & 1.19 & 0.59 & 0.98 & 0.63 \\
\hline $\mathrm{Al} / \mathrm{N}+\mathrm{MOET}$ & 1.73 & 0.37 & 1.48 & 0.51 & 1.27 & 0.57 \\
\hline $\mathrm{Al} / \mathrm{N}$ & 2.16 & 0.32 & 2.02 & 0.34 & 1.90 & 0.41 \\
\hline \multicolumn{7}{|l|}{ Late trait sheep } \\
\hline $\mathrm{Al} / \mathrm{N}+\mathrm{MOET}+\mathrm{JIVET}(\mathrm{GS})$ & 1.07 & 0.46 & 1.03 & 0.51 & 1.01 & 0.58 \\
\hline $\mathrm{Al} / \mathrm{N}+\mathrm{MOET}(\mathrm{GS})$ & 1.64 & 0.34 & 1.43 & 0.39 & 1.41 & 0.46 \\
\hline Al/N (GS) & 2.25 & 0.25 & 2.08 & 0.29 & 1.96 & 0.35 \\
\hline $\mathrm{Al} / \mathrm{N}+\mathrm{MOET}+\mathrm{JIVET}$ & 1.49 & 0.20 & 1.42 & 0.21 & 1.32 & 0.22 \\
\hline $\mathrm{Al} / \mathrm{N}+\mathrm{MOET}$ & 3.20 & 0.21 & 3.12 & 0.22 & 3.03 & 0.23 \\
\hline $\mathrm{Al} / \mathrm{N}$ & 3.24 & 0.14 & 3.13 & 0.15 & 3.06 & 0.15 \\
\hline \multicolumn{7}{|l|}{ Early trait beef } \\
\hline $\mathrm{Al} / \mathrm{N}+\mathrm{MOET}+\mathrm{JIVET}(\mathrm{GS})$ & 2.28 & 0.41 & 2.1 & 0.49 & 1.99 & 0.57 \\
\hline $\mathrm{Al} / \mathrm{N}+\mathrm{MOET}(\mathrm{GS})$ & 2.93 & 0.36 & 2.71 & 0.41 & 2.59 & 0.48 \\
\hline $\mathrm{Al} / \mathrm{N}(\mathrm{GS})$ & 3.92 & 0.27 & 3.69 & 0.29 & 3.70 & 0.34 \\
\hline $\mathrm{Al} / \mathrm{N}+\mathrm{MOET}+\mathrm{JIVET}$ & 2.63 & 0.25 & 2.27 & 0.31 & 2.19 & 0.36 \\
\hline $\mathrm{Al} / \mathrm{N}+\mathrm{MOET}$ & 3.10 & 0.26 & 2.9 & 0.3 & 2.68 & 0.34 \\
\hline $\mathrm{Al} / \mathrm{N}$ & 4.04 & 0.20 & 3.92 & 0.21 & 3.86 & 0.26 \\
\hline \multicolumn{7}{|l|}{ Late trait beef } \\
\hline $\mathrm{Al} / \mathrm{N}+\mathrm{MOET}+\mathrm{JIVET}(\mathrm{GS})$ & 2.38 & 0.36 & 2.24 & 0.41 & 2.14 & 0.42 \\
\hline $\mathrm{Al} / \mathrm{N}+\mathrm{MOET}(\mathrm{GS})$ & 3.10 & 0.29 & 2.97 & 0.33 & 2.86 & 0.35 \\
\hline Al/N (GS) & 4.08 & 0.22 & 3.93 & 0.26 & 3.92 & 0.28 \\
\hline $\mathrm{Al} / \mathrm{N}+\mathrm{MOET}+$ JIVET & 2.72 & 0.21 & 2.58 & 0.23 & 2.51 & 0.24 \\
\hline $\mathrm{Al} / \mathrm{N}+\mathrm{MOET}$ & 3.36 & 0.21 & 3.19 & 0.23 & 3.00 & 0.23 \\
\hline $\mathrm{Al} / \mathrm{N}$ & 4.18 & 0.17 & 4.15 & 0.17 & 4.03 & 0.18 \\
\hline \multicolumn{7}{|l|}{ Dairy } \\
\hline $\mathrm{Al}+\mathrm{MOET}+\mathrm{JIVET}(\mathrm{GS})$ & 1.92 & 0.54 & 1.86 & 0.58 & 1.79 & 0.67 \\
\hline$A I+\operatorname{MOET}(G S)$ & 2.66 & 0.40 & 2.58 & 0.44 & 2.46 & 0.51 \\
\hline $\mathrm{Al}(\mathrm{GS})$ & 3.55 & 0.28 & 3.41 & 0.32 & 3.35 & 0.35 \\
\hline $\mathrm{Al}+\mathrm{MOET}+$ JIVET & 4.09 & 0.24 & 3.97 & 0.26 & 3.91 & 0.28 \\
\hline $\mathrm{Al}+\mathrm{MOET}$ & 4.62 & 0.24 & 4.52 & 0.26 & 4.47 & 0.28 \\
\hline Al & 5.55 & 0.18 & 5.39 & 0.21 & 5.28 & 0.24 \\
\hline
\end{tabular}

All standard errors of means (SEM) were less than 0.11 and less than 0.003 for all breeding programs for generation interval and genetic gain, respectively

specific inbreeding rates. We were then able to choose specific inbreeding rates per generation to compare scenarios. While genetic gain somewhat plateaued when the rate of inbreeding increased to $1 \%$ per generation (Table 3), managers of breeding programs must decide which point on the frontier suits their breeding objective.

Our study is unique in that it uses OCS to optimize genetic gain with inbreeding in livestock breeding programs that use female reproductive technologies. It also optimally assigned reproductive technologies according to how much each mating contributes to the objective function of maximizing gain while penalizing inbreeding. Table 2 demonstrates the proportion of females that were allocated to different reproductive technologies. We observed that, with the added accuracy that is provided by GS, the proportions of MOET allocations did not change in $\mathrm{AI}+\mathrm{MOET}$ breeding programs. However we observed that with the use of GS in AI + MOET + JIVET breeding programs increased JIVET allocations by up to 86,20 and $88 \%$ and decreased MOET allocations by up 
Table 4 Increase (\%) in rate of genetic gain per year of breeding programs using MOET and JIVET compared to the $\mathrm{Al} / \mathrm{N}$ breeding program (Repro) and increase (\%) in rate of genetic gain per year from the use of genomic selection (GS) on each breeding program at various rates of inbreeding $( \pm 0.05 \%)$ per generation for sheep, beef and dairy traits

\begin{tabular}{|c|c|c|c|c|c|c|}
\hline \multirow[t]{2}{*}{ Inbreeding rate (\%/gen) } & \multicolumn{2}{|l|}{0.5} & \multicolumn{2}{|l|}{1.0} & \multicolumn{2}{|c|}{ Unpenalized } \\
\hline & Repro & GS & Repro & GS & Repro & GS \\
\hline \multicolumn{7}{|l|}{ Early trait sheep } \\
\hline $\mathrm{Al} / \mathrm{N}+\mathrm{MOET}+\mathrm{JIVET}(\mathrm{GS})$ & 72 & 68 & 75 & 31 & 70 & 35 \\
\hline $\mathrm{Al} / \mathrm{N}+\mathrm{MOET}(\mathrm{GS})$ & 10 & 16 & 43 & 24 & 50 & 32 \\
\hline $\mathrm{Al} / \mathrm{N}(\mathrm{GS})$ & & 22 & & 29 & & 22 \\
\hline $\mathrm{Al} / \mathrm{N}+\mathrm{MOET}+\mathrm{JIVET}$ & 25 & & 74 & & 54 & \\
\hline $\mathrm{Al} / \mathrm{N}+\mathrm{MOET}$ & 16 & & 50 & & 39 & \\
\hline \multicolumn{7}{|l|}{ Late trait sheep } \\
\hline $\mathrm{Al} / \mathrm{N}+\mathrm{MOET}+\mathrm{JIVET}(\mathrm{GS})$ & 84 & 130 & 76 & 143 & 66 & 163 \\
\hline $\mathrm{Al} / \mathrm{N}+\mathrm{MOET}(\mathrm{GS})$ & 36 & 62 & 34 & 77 & 31 & 100 \\
\hline $\mathrm{Al} / \mathrm{N}(\mathrm{GS})$ & & 79 & & 93 & & 133 \\
\hline $\mathrm{Al} / \mathrm{N}+\mathrm{MOET}+\mathrm{JIVET}$ & 43 & & 40 & & 47 & \\
\hline $\mathrm{Al} / \mathrm{N}+\mathrm{MOET}$ & 50 & & 47 & & 53 & \\
\hline \multicolumn{7}{|l|}{ Early trait beef } \\
\hline $\mathrm{Al} / \mathrm{N}+\mathrm{MOET}+\mathrm{JIVET}(\mathrm{GS})$ & 52 & 64 & 69 & 58 & 68 & 58 \\
\hline $\mathrm{Al} / \mathrm{N}+\mathrm{MOET}(\mathrm{GS})$ & 33 & 38 & 41 & 37 & 41 & 41 \\
\hline $\mathrm{Al} / \mathrm{N}(\mathrm{GS})$ & & 35 & & 38 & & 31 \\
\hline $\mathrm{Al} / \mathrm{N}+\mathrm{MOET}+\mathrm{JIVET}$ & 25 & & 48 & & 38 & \\
\hline $\mathrm{Al} / \mathrm{N}+\mathrm{MOET}$ & 30 & & 43 & & 31 & \\
\hline \multicolumn{7}{|l|}{ Late trait beef } \\
\hline $\mathrm{Al} / \mathrm{N}+\mathrm{MOET}+\mathrm{JIVET}(\mathrm{GS})$ & 64 & 71 & 58 & 78 & 50 & 75 \\
\hline $\mathrm{Al} / \mathrm{N}+\mathrm{MOET}(\mathrm{GS})$ & 32 & 38 & 27 & 43 & 25 & 52 \\
\hline $\mathrm{Al} / \mathrm{N}(\mathrm{GS})$ & & 29 & & 53 & & 56 \\
\hline $\mathrm{Al} / \mathrm{N}+\mathrm{MOET}+\mathrm{JIVET}$ & 24 & & 35 & & 33 & \\
\hline $\mathrm{Al} / \mathrm{N}+\mathrm{MOET}$ & 24 & & 35 & & 28 & \\
\hline \multicolumn{7}{|l|}{ Dairy } \\
\hline $\mathrm{Al}+\mathrm{MOET}+\mathrm{JIVET}(\mathrm{GS})$ & 93 & 125 & 81 & 123 & 91 & 139 \\
\hline$A l+\operatorname{MOET}(G S)$ & 43 & 67 & 38 & 69 & 46 & 82 \\
\hline $\mathrm{Al}(\mathrm{GS})$ & & 56 & & 52 & & 46 \\
\hline $\mathrm{Al}+\mathrm{MOET}+\mathrm{JIVET}$ & 33 & & 24 & & 17 & \\
\hline $\mathrm{Al}+\mathrm{MOET}$ & 33 & & 24 & & 17 & \\
\hline
\end{tabular}

to 38,15 and $20 \%$ for sheep, beef cattle and dairy cattle breeding programs, respectively. In conjunction with a shift in the selection of more JIVET candidates, we observed a decrease in generation intervals (Table 3). We also observed that the number of males selected each year differed only slightly between programs (Table 2). It should be noted that males are generally used below their maximum reproductive capacity. The use of males below their natural or artificial insemination capabilities was needed to maintain diversity without sacrificing too much genetic gain. The concept of reducing inbreeding while implementing reproductive technologies by using more sires under their reproductive capacity has been described previously by Kinghorn [33], Arendonk and
Bijma [34], Pryce et al. [14] and Lillehammer et al. [35] in dairy, and by Brash et al. [8] in sheep breeding schemes.

\section{Comparing with previous studies}

Our study estimated that the benefit of MOET in sheep breeding programs without using GS, was up to $50 \%$ while maintaining the rate of inbreeding at $1 \%$ per generation. Previous studies $[7,8]$ using MOET in sheep breeding programs also predicted such gains but without restricting inbreeding rates. Our beef MOET breeding programs achieved 35 to $43 \%$ more genetic gain than AI programs without GS which was less than previous studies, which reported extra gains of 67 to $138 \%$ $[7,9,10]$, but we achieved these gains at the same rate 
of inbreeding per generation, while rates of inbreeding increased by 87 to $300 \%$ in the aforementioned studies. Use of MOET in our dairy breeding program resulted in $24 \%$ extra genetic gain without increasing the rate of inbreeding. This is similar to the values reported by Kinghorn [33] and Leitch et al. [3], who estimated similar gains in dairy cattle nucleus breeding programs that implemented MOET compared to traditional AI nucleus breeding programs but with larger increases in rates of inbreeding (1.7 to $4.2 \%$ increase per year). Without GS, all traits and species benefited from the use of MOET. However, except for the early measured trait in sheep, which yielded 4 to $10 \%$ greater annual genetic gain, the use of JIVET without GS did not yield extra genetic gain compared to AI + MOET programs in late trait sheep, beef and dairy cattle breeding programs, although some JIVET matings were allocated to juveniles (Table 2). The lower allocation of JIVET matings is likely due to the low accuracy of EBV and the high correlation between EBV of full siblings at a young age. This demonstrates that, even without accounting for the additional cost of JIVET, this technology may not give an advantage to breeding programs when using optimal contribution selection across age classes, at least without GS.

Previous studies have also evaluated breeding programs that implement female reproductive technologies with GS in comparison to traditional programs. Pryce et al. [14] deterministically modeled a closed nucleus of Holstein cattle in which 300 juvenile females that were submitted to JIVET were mated only to genomically selected sires and compared the rates of genetic gain and inbreeding to a progeny-testing AI breeding program. The JIVET program resulted in a $131 \%$ increase in genetic gain and a $7 \%$ decrease in rate of inbreeding, which they obtained by increasing the number of sires of bulls and cows. Their breeding program resulted in 0.59 genetic standard deviations of genetic gain per year at a $0.17 \%$ rate of inbreeding per year. The most comparable scenario in our study is the AI + MOET + JIVET (GS) program vs. AI. With a rate of inbreeding of $0.17 \%$ per year for both programs, we observed that AI + MOET + JIVET (GS) resulted in a $145 \%$ greater genetic gain per year than the AI breeding program, with gains of 0.54 and 0.22 genetic standard deviations per year, respectively (Fig. 5). The genetic gain that we obtained in the dairy cattle AI + MOET + JIVET (GS) breeding program was not quite as large as that in Pryce et al. [14]. This could be due to our stochastic simulation also using MOET and AI technologies which resulted in higher generation intervals and lower selection intensities compared to Pryce et al.s [14] $100 \%$ JIVET each year.

\section{Rates of inbreeding}

Breeding programs resulting in high rates of inbreeding should be avoided due to the likelihood of declines in fitness $[36,37]$ and homozygous recessive genotypes that are lethal [38]. However, if inbreeding is penalized too heavily, genetic diversity is maintained but with low rates of genetic gain (Figs. 1, 2, 3, 4, 5). Therefore, a compromise must be made to achieve desirable amounts of genetic gain without increasing inbreeding too much. Figures 1, 2, 3, 4 and 5 show rates of inbreeding per year, but past studies suggest using inbreeding rate per generation as a metric as it can be used to compare different breeding programs with different generation intervals. Bijma [39] suggested restricting rates of inbreeding to $1 \%$ per generation, which was supported by Buch et al. [40].This desired rate of inbreeding will differ between producers due to varying concerns about the importance of inbreeding, the size of the nucleus, the ability to import unrelated animals into the nucleus, the effective population size of the breed as a whole, and the incidence of recessive homozygous genetic diseases [41].

\section{Simulation restrictions}

In this study, GEBV were simulated as a correlated trait with a heritability of 1 and a genetic correlation with the trait equal to the accuracy of the GEBV [24]. Genomic selection can also be simulated by simulating quantitative trait loci (QTL) and genetic markers. However, because we did not simulate genotypes, predicting the linkage disequilibrium (LD) patterns across generations [42] between markers and QTL was not addressed in our simulations. Family sizes that increase in a nucleus over generations through the use of MOET and JIVET could slightly increase the accuracy of the individual GEBV of those family members [43]. However, predicting the changes in gene frequencies of the nucleus population using an infinitesimal model could be difficult to determine over a period longer than three generations [44]. An alternative method that simulates the actual marker genotypes could be used to capture the change in LD structure over time due to selection [45]. Some studies [46-48] have studied the efficacy of genomic selection when performed over many generations, and where only a few QTL control genetic variation. They suggest that the effects of markers do not change but the proportion of genetic variance explained by them will decline, which means that the effects of genomic selection may be over-estimated in our simulations. However, it has been suggested that hundreds or thousands of QTL may control variation for a given trait $[49,50]$. Heffner et al. [51] demonstrated that if all QTL effects are small, as in an 
infinitesimal model, genomic selection could maintain accuracies over multiple generations due to the change in LD between QTL and markers being less important over a longer time period. Therefore, given both sides of the argument it is difficult to predict whether the method of Dekkers [17] over- or under-estimates genetic gains from genomic selection.

In our study, we used a pedigree-derived relationships matrix (A) to measure inbreeding and also during OCS. Some authors have shown that using a genomic relationship matrix $(\mathbf{G})$ in OCS has some advantages over using $\mathbf{A}$ by achieving similar rates of genetic gain with slightly lower rates of inbreeding $[52,53]$. This is achieved because $\mathbf{G}$ accounts for differences in the level of relatedness within families. Using $\mathbf{G}$ would however increase computing time for an already time-consuming simulation.

This study did not take the costs of technology into account. If they were, we expect that the use of reproductive technologies would decrease. In some cases, reproductive technologies were assigned although the additional genetic benefit was limited, in particular when inbreeding was highly penalized. Therefore, this study evaluated the maximum use and benefit in terms of genetic gain. Including costs will, however, give a more realistic picture of potential use. A cost benefit assessment will also focus more on how genetic gain is translated into actual monetary benefit for the breeder who carries the burden of the additional investment.

\section{Conclusions}

Reproductive technologies combined with genomic selection can substantially enhance rates of genetic gain without compromising rates of inbreeding when optimal contribution selection is used with an incurred penalty on future co-ancestry. Without genomic selection, the use of JIVET in conjunction with MOET is not beneficial. These results suggest that synergies exist between the applications of reproductive technologies, genomic selection and optimal contribution selection. Optimal contribution selection was an effective tool in optimizing the allocations of combined reproductive technologies. The full exploration of the frontier between inbreeding vs. genetic gain production was facilitated by applying a range of penalties to co-ancestry of selection candidates.

\footnotetext{
Authors' contributions

TG wrote and carried out the simulations, carried out statistical analysis and drafted the manuscript. SC, AS assisted in computer coding and participated in the design of the study. JvdW conceived the idea of this study, participated in the design of the study and assisted with computer coding. All authors read and approved the final manuscript.
}

\footnotetext{
Author details

${ }^{1}$ Sheep Cooperative Research Centre, Armidale 2351, Australia. ${ }^{2}$ School of Environmental and Rural Science, University of New England,
}

Armidale 2351, Australia. ${ }^{3}$ Animal Genetics and Breeding Unit, Armidale 2351, Australia.

\section{Acknowledgements}

The authors acknowledge the University of New England and Cooperative Research Centre for Sheep Industry Innovation for funding.

\section{Compliance with ethical guidelines}

\section{Competing interests}

The authors declare that they have no competing interests.

Received: 13 August 2014 Accepted: 3 September 2015 Published online: 14 September 2015

\section{References}

1. Meuwissen THE, Hayes BJ, Goddard ME. Prediction of total genetic value using genome-wide dense marker maps. Genetics. 2001;157:1819-29.

2. Nicholas FW, Smith C. Increased rates of genetic change in dairy cattle by embryo transfer and splitting. Anim Sci. 1983;36:341-53.

3. Leitch HW, Smith C, Burnside EB, Quinton M. Genetic response and inbreeding with different selection methods and mating designs for nucleus breeding programs of dairy cattle. J Dairy Sci. 1994;77:1702-18.

4. Gearheart WW, Smith C, Teepker G. Multiple ovulation and embryo manipulation in the improvement of beef cattle: relative theoretical rates of genetic change. J Anim Sci. 1989;67:2863-71.

5. Land RB, Hill WG. The possible use of superovulation and embryo transfer in cattle to increase response to selection. Anim Sci. 1975;21:1-12.

6. Smith C. Use of embryo transfer in genetic improvement of sheep. Anim Sci. 1986;42:81-6.

7. Horton B. A method of using a genetic algorithm to examine the optimum structure of the Australian sheep breeding industry: open-nucleus breeding systems MOET and Al. Aust J Exp Agr. 1996;36:249-58.

8. Brash LD, Wray NR, Goddard ME. Use of MOET in Merino breeding programmes: a practical and economic appraisal. Anim Sci. 1996;62:241-54.

9. Wray NR, Simm G. The use of embryo transfer to accelerate genetic improvement in beef cattle. In: Proceedings of the 4th World Congress on Genetics Applied to Livestock Production, 23-27 July 1990: Edinburgh; 1990, p. 315-8.

10. Villanueva B, Woolliams JA, Simm G. The effect of improved reproductive performance on genetic gain and inbreeding in MOET breeding schemes for beef cattle. Genet Sel Evol. 1995;27:347-63.

11. Meuwissen THE, Goddard ME. The use of marker haplotypes in animal breeding schemes. Genet Sel Evol. 1996;28:161-76.

12. Clark SA, Kinghorn BP, Hickey JM, van der Werf JHJ. The effect of genomic information on optimal contribution selection in livestock breeding programs. Genet Sel Evol. 2013;45:44.

13. Pedersen LD, Kargo M, Berg P, Voergaard J, Buch LH, Sørensen AC. Genomic selection strategies in dairy cattle breeding programmes: sexed semen cannot replace multiple ovulation and embryo transfer as superior reproductive technology. J Anim Breed Genet. 2012;129:152-63.

14. Pryce JE, Goddard ME, Raadsma HW, Hayes BJ. Deterministic models of breeding scheme designs that incorporate genomic selection. J Dairy Sci. 2010;93:5455-66.

15. Wray NR, Goddard ME. Increasing long-term response to selection. Genet Sel Evol. 1994;26:431-51.

16. Meuwissen THE. Maximizing the response of selection with a predefined rate of inbreeding. J Anim Sci. 1997;75:934-40.

17. Dekkers JCM. Prediction of response to marker-assisted and genomic selection using selection index theory. J Anim Breed Genet. 2007;124:331-41.

18. Swan AA, Brown DJ, Daetwyler HD, Hayes BJ, Kelly M, Moghaddar N, et al. Genomic evaluations in the Australian sheep industry. In: Proceedings of the 10th World Congress on Genetics Applied to Livestock Production: 17-22 August 2014; Vancouver; 2014, p. 334.

19. Bolormaa S, Pryce JE, Kemper K, Savin K, Hayes BJ, Barendse W, et al. Accuracy of prediction of genomic breeding values for residual feed 
intake and carcass and meat quality traits in Bos taurus, Bos indicus, and composite beef cattle. J Anim Sci. 2013;91:3088-104.

20. Hayes BJ, Bowman PJ, Chamberlain AJ, Verbyla K, Goddard ME. Accuracy of genomic breeding values in multi-breed dairy cattle populations. Genet Sel Evol. 2009;41:51.

21. Price K, Storn R. Differential evolution. Dr Dobb's J. 2004;78:18-24.

22. Bunter $\mathrm{KL}$, Brown DJ. Yearling and adult expressions of reproduction in maternal sheep breeds are genetically different traits. In Proceedings of the twentieth Association for Advancement in Animal Breeding and Genetics: 20-23 October 2013: Napier; 2013, p. 82-85.

23. Armstrong DT, Kotaras PJ, Earl C. Advances in production of embryos in vitro from juvenile and prepubertal oocytes from the calf and lamb. Reprod Fertil Dev. 1997;9:333-9.

24. Houghton PL, Lemenager P, Horstman LA, Hendrix KS, Moss GE. Effects of body composition, pre-and postpartum energy level and early weaning on reproductive performance of beef cows and preweaning calf gain. J Anim Sci. 1990;68:1438-46.

25. Buckley F, O'Sullivan K, Mee JF, Evans RD, Dillon P. Relationships among milk yield, body condition, cow weight, and reproduction in springcalved Holstein-Friesians. J Dairy Sci. 2003;86:2308-19.

26. Hasler JF. Factors affecting frozen and fresh embryo transfer pregnancy rates in cattle. Theriogenology. 2001;56:1401-15.

27. Nicholas FW. Genetic improvement through reproductive technology. Anim Reprod Sci. 1996:42:205-14.

28. Bulmer MG. The effect of selection on genetic variability. Am Nat. 1971;105:201-11.

29. Bijma P. Accuracies of estimated breeding values from ordinary genetic evaluations do not reflect the correlation between true and estimated breeding values in selected populations. J Anim Breed Genet. 2012;129:345-58.

30. van der Werf JHJ. Potential benefit of genomic selection in sheep. In: Proceedings of the 18th Conference of the Association for the Advancement of Animal Breeding and Genetics: 28 September-1 October 2009: Barossa Valley; 2009, p. 38-41.

31. Meuwissen THE, Sonesson AK. Maximizing the response of selection with a predefined rate of inbreeding: overlapping generations. J Anim Sci. 1998;76:2575-83.

32. Grundy B, Villanueva B, Woolliams JA. Dynamic selection for maximizing response with constrained inbreeding in schemes with overlapping generations. Anim Sci. 2000;70:373-82.

33. Kinghorn BP, Smith C, Dekkers JCM. Potential genetic gains in dairy cattle with gamete harvesting and in vitro fertilization. J Dairy Sci. 1991;74:611-22.

34. van Arendonk JAM, Bijma P. Factors affecting commercial application of embryo technologies in dairy cattle in Europe-a modelling approach. Theriogenology. 2003;59:635-49.

35. Lillehammer M, Meuwissen THE, Sonesson AK. A comparison of dairy cattle breeding designs that use genomic selection. J Dairy Sci. 2011;94:493-500.

36. Smith LA, Cassell BG, Pearson RE. The effects of inbreeding on the lifetime performance of dairy cattle. J Dairy Sci. 1998;81:2729-37.
37. Van Raden PM, Olson KM, Null DJ, Hutchison JL. Harmful recessive effects on fertility detected by absence of homozygous haplotypes. J Dairy Sci. 2011;94:6153-61.

38. Shariflou MR, Wade CM, Windsor PA, Tammen I, James JW, Nicholas FW. Lethal genetic disorder in Poll Merino/Merino sheep in Australia. Aust Vet J. 2011;89:254-9.

39. Bijma P. Long-term genetic contributions. PhD Thesis, Wageningen University, Department of Animal Sciences; 2000

40. Buch LH, Sørensen MK, Berg P, Pedersen LD, Sørensen AC. Genomic selection strategies in dairy cattle: strong positive interaction between use of genotypic information and intensive use of young bulls on genetic gain. J Anim Breed Genet. 2012;129:138-51.

41. Goddard ME. Optimal effective population size for the global population of Black and White dairy cattle. J Dairy Sci. 1992;75:2902-11.

42. Farnir F, Coppieters W, Arranz JJ, Berzi P, Cambisano N, Grisart B, et al. Extensive genome-wide linkage disequilibrium in cattle. Genome Res. 2000:10:220-7.

43. Risch $\mathrm{N}$, Teng J. The relative power of family-based and case-control designs for linkage disequilibrium studies of complex human diseases I. DNA pooling. Genome Res. 1998;8:1273-88.

44. Meuwissen THE. Optimisation of dairy cattle breeding plans with increased female reproductive rates. PhD Thesis, Wageningen University, Research Institute for Animal Production; 1990.

45. VanRaden PM. Efficient methods to compute genomic predictions. J Dairy Sci. 2008;91:4414-23.

46. Muir WM. Comparison of genomic and traditional BLUP-estimated breeding value accuracy and selection response under alternative trait and genomic parameters. J Anim Breed Genet. 2007;124:342-55.

47. Sonesson AK, Meuwissen THE. Testing strategies for genomic selection in aquaculture breeding programs. Genet Sel Evol. 2009;41:37.

48. Zhang XS, Hill WG. Predictions of patterns of response to artificial selection in lines derived from natural populations. Genetics. 2005;169:411-25.

49. Hayes BJ, Chamberlain AJ, McPartlan H, Macleod I, Sethuraman L, Goddard ME. Accuracy of marker-assisted selection with single markers and marker haplotypes in cattle. Genet Res. 2007;89:215-20.

50. Goddard ME. Genomic selection: prediction of accuracy and maximisation of long term response. Genetica. 2009;136:245-57.

51. Heffner EL, Jannink JL, Sorrells ME. Genomic selection accuracy using multifamily prediction models in a wheat breeding program. Plant Genome. 2011:4:65-75.

52. Dagnachew BS, Meuwissen THE. An iterative algorithm for optimum contribution selection in large scale breeding programs. In: Proceedings of the 10th World Congress of Genetics Applied to Livestock Production: 15-22 August 2014; Vancouver; 2014, p. 023.

53. Nielsen HM, Sonesson AK, Meuwissen THE. Optimum contribution selection using traditional best linear unbiased prediction and genomic breeding values in aquaculture breeding schemes. J Anim Sci. 2011;89:630-8.

\section{Submit your next manuscript to BioMed Central and take full advantage of:}

- Convenient online submission

- Thorough peer review

- No space constraints or color figure charges

- Immediate publication on acceptance

- Inclusion in PubMed, CAS, Scopus and Google Scholar

- Research which is freely available for redistribution

Submit your manuscript at

www.biomedcentral.com/submit
C Biomed Central 